ISSN 1397-4831

WORKING PAPER 03-27

Aycan Çelikaksoy, Helena Skyt Nielsen and Mette Verner

Marriage Migration:

Just another case of positive assortative matching?

Department of Economics

Aarhus School of Business 


\title{
Marriage Migration: Just another case of positive assortative matching?*
}

\author{
Aycan Çelikaksoy ${ }^{\dagger}$, \\ Helena Skyt Nielsen \\ and \\ Mette Verner ${ }^{\S}$
}

\begin{abstract}
It is a stylized fact that marriage formation generally involves positive assortative matching (PAM) on education. We test whether this is also the case for immigrants who tend to import their spouses and potentially use education as an exchange mechanism. We find that only women match positively on education. For Turks the results robustly confirm PAM, whereas for Pakistanis there is no evidence of PAM. For men there is local support to the exchange hypothesis, since cultural assimilation or conflicts with parents, through less spouse import, increase the likelihood of marrying a highly educated spouse.
\end{abstract}

JEL classification: $\mathrm{J} 12, \mathrm{~J} 15$

Keywords: assortative matching, homogamy, exchange, marriage migration, spouse import.

\footnotetext{
${ }^{*}$ We appreciate financial support from the Graduate School for Integration, Production and Welfare and the Centre for Research in Social Integration and Marginalization (financed by the Social Science Research Council). We are highly indebted to Shelly Lundberg, Michael Svarer and Nina Smith for detailed comments. Furthermore, we are grateful to Peter Jensen, Lise Togeby, Torben Tranæs as well as participants at EALE, at seminars at the Aarhus School of Business and SFI for their comments. We thank Julie Kracht and David Skovmand for research assistance. The usual disclaimer applies.

${ }^{\dagger}$ CIM \& Dept. of Economics, Aarhus School of Business, Prismet, Silkeborgvej 2, DK-8000 Aarhus C, Denmark. Phone: +45 8948 6182. Email: $\underline{\text { Cel@asb.dk. }}$

$\$$ CIM \& Dept. of Economics, University of Aarhus, Ndr. Ringgade 1, DK-8000 Aarhus C, Denmark. Phone: +45 89421594. Email: Hnielsen@econ.au.dk.

$\S$ CIM \& Dept. of Economics, Aarhus School of Business, Prismet, Silkeborgvej 2, DK-8000 Aarhus C, Denmark. Phone: +45 8948 6416. Email: Mev@asb.dk.
} 


\section{Introduction}

A large literature is concerned with the correlation between levels of education of two spouses. In theory the correlation may be positive or negative because education of the two spouses may be either complements or substitutes in production of marital capital (Becker 1973). However, the empirical literature agrees that the correlation is positive, and therefore the question boils down to an issue of the degree of homogamy over time and across countries (e.g. Smits et al., 1998; Halpin and Chan, 2002; Mare, 1991). Only few studies look at the issue of educational homogamy in the case of interethnic marriages, but also these studies find support for positive assortative mating by education (Lievens, 1998; Qian, 1999; Qian et al., 2001; Kalmijn, 1993). No studies have addressed this issue in relation to marriage migration or imported spouses.

Studying marriage migration between less developed countries and developed countries, the issue of assortative matching on education is particularly interesting because education may be exchanged for other resources. Marriage migration between a less developed country and a developed country may be seen as an exchange of favourable living conditions against, for instance, a high bride price or a high education (Gitmez and Wilpert, 1987; Böcker, 1994, 1995; Van Amersfoort, 1995). This is a special case of the exchange hypothesis as posed by Davis (1941) and Merton (1941). They hypothesize that two spouses exchange resources, e.g. higher status for good looks or money, by their marriage. In Becker's terminology, this would be consistent with negative or non-positive assortative matching on education since the educations of the two spouses would be substitutes. Qian (1999) investigates whether interethnic marriage in the US may be explained by immigrants exchanging high education for a white spouse, and he rejects this hypothesis.

In this paper, we investigate the degree of educational homogamy between spouses in couples involving at least one immigrant. We focus on the education of couples involving Turkish, Pakistani and Ex-Yugoslavian immigrants in Denmark, whose marriage behaviour is described in detail by Celikaksoy (2003). By use of a survey from 1999, we test two hypotheses; the hypothesis of positive assortative matching (PAM) and the exchange hypothesis. Regarding PAM, the idea is that if the stylized fact of positive assortative matching also describes marriage behaviour of immigrants in Denmark, one would expect that individuals in the upper (lower) end of the educational distribution tend to marry other individuals from the upper (lower) part of the educational distribution for that particular demographic group. We test the exchange hypothesis by studying whether individuals tend to get a spouse further up or down in the educational distribution by importing a spouse. If the individual tends to get a better educated spouse as a result of spouse import, it indicates that education of the imported spouse is traded for good living conditions in the host country (Denmark). If on the other hand, the individual tends to get a less educated spouse as a result of spouse import, it indicates that the imported spouse has some favourable attributes that compensate for the lack of education. 
The paper is organized as follows: Section 2 sketches the theoretical framework. Section 3 describes the data set and variables used. Section 4 presents the empirical analyses to test the two main hypotheses, the PAM hypothesis and the exchange hypothesis. Section 5 concludes.

\section{A simple theory of marriage and marriage migration}

In this section, we sketch a theoretical framework describing the marriage decision of immigrants. In the context of immigrants in a host country like Denmark, the marriage decision consists of two simultaneous choices. As in standard marriage decisions, the individuals decide whom to marry in terms of observed characteristics/qualifications. In addition, they decide from which country the spouse should come, that is the source country or host country. The decision to marry and the decision to import a marriage migrant are assumed to be simultaneous decisions that depend upon the characteristics that are brought into a marriage by the spouses. The characteristics of the spouses are summarized in marital capital, which includes for instance physical capital, financial capital (such as bride price or dowry) and human capital (such as health or education).

\subsection{Marriage model}

The theoretical background for our empirical model for marriage migration is to be found in the Becker model (1973). It builds on the assumption that marriage markets in the source country (inhabitants indexed $s$ ) and in the host country (inhabitants indexed $i$ ) are competitive. ${ }^{1}$

The decision to marry is considered as a decision taken by the household of the young individual. An immigrant household considering marriage has to choose between two alternative marriage markets. When a household chooses to enter another marriage market than the local marriage market, this reflects that the utility of a match in that marriage market is higher than the utility of a match with a person from the local marriage market (or any other relevant alternative). ${ }^{2}$ For marriage migration actually to take place, this must be the case for both households. ${ }^{3}$

It is assumed that the benefit of the match can be separated between the two spouses. The utility of the two individuals is denoted $U_{j k}^{j}$ for $j, k=i, s$, where $j$ refers to the household

\footnotetext{
${ }^{1}$ We abstract from search costs, which are really distributed among many agents other than the immigrant household, agents who are involved in the match-making process, namely, relatives, neighbours and friends.

${ }^{2}$ If the quality of a match is uncertain, the relevant comparison would be between expected utilities plus a risk premium. In that case, one reason for choosing marriage migration could be risk aversion combined with better information as concerns the norms and values of potential spouses from the country of origin. Some notes on marriage and risk are given by Weiss (1997).

${ }^{3}$ The rate of success in a given market depends on the accessibility of the market. For the case of marriage migration, the availability of contact to relatives or villagers in the country of origin in the exterior marriage market is crucial.
} 
under consideration (immigrant, $i$, or source country person, $s$ ) and $k$ denotes the origin of the partner. The probability of a match involving marriage migration may be written as

$$
\operatorname{Prob}(\{i, s\})=P\left(U_{i s}^{i} \geq U_{i i}^{i} \wedge U_{i s}^{s} \geq U_{s s}^{s}\right)
$$

namely the joint probability that both households prefer a marriage involving a person from the other marriage market. The utility functions, which may differ across households, are assumed to depend on the characteristics of the individuals in terms of marital capital $\left(M_{j}, M_{k}\right)$ :

$$
U_{j k}^{j}=\left\{\begin{array}{l}
f^{j}\left(M_{j}, M_{k}\right) \text { for } j=k \\
g^{j}\left(M_{j}, M_{k}\right) \text { for } j \neq k
\end{array}\right.
$$

It is seen that the functional form of the utility functions $(f($.$) and g()$.$) is allowed to differ$ across households and across marriage markets. The probability that marriage migration is optimal for a given household (i.e. $U_{j k}^{j} \geq U_{j j}^{j}$ ) is high if the potential spouse from the exterior marriage market has favorable characteristics $\left(M_{k}\right)$ that contribute to the utility of his/her spouse. Similarly, if the household for given values of marital capital, $\left(M_{j}, M_{k}\right)$, favours marriage migration, that would also increase the probability of marriage migration. This is the case if the functional form of $g($.) assigns a higher level of utility to a given combination of $\left(M_{j}, M_{k}\right)$ than $f($.$) .$

It is important to separate the determinants of the utility of marriage migration into marital capital, reflected in $\left(M_{j}, M_{k}\right)$, and preferences, that is the functional form of the utility function, $g($.$) . The utility function probably differs across gender, because it depends on$ whether the individual is looking for a breadwinner or a caretaker. In our empirical analysis, marital capital is mainly education, whereas the preference parameters are going to be approximated by country of origin, gender and a set of attitudinal variables. These variables can be viewed as proxies for the norms or attitudes of the immigrant household, or they can be viewed as correlated with an imposed responsibility of the immigrant household to help their countrymen to access the host country.

\subsection{Two testable hypotheses}

The optimal combination of marital capital depends on whether the marital capital of the two spouses is complements or substitutes. Becker (1973) predicts that for some characteristics (e.g. physical appearance and intelligence) positive assortative matching (PAM) occurs and for others (e.g. earnings and labour supply) negative assortative matching is likely to occur. Below, we focus on assortative mating on education at the time of marriage, since education is the only variable that is observed for both partners in the empirical analysis. 
In theory, either negative or positive assortative mating on education could be present. Negative or non-positive assortative mating would confirm with the exchange hypothesis dating back to Davis (1941) and Merton (1941), which indicates that two spouses exchange resources (e.g. higher status for good looks or money) by their marriage. Qian (1999) investigates whether interethnic marriage in the US may be explained by immigrants exchanging high education for a white spouse. He rejects this hypothesis. In fact, no empirical study to our knowledge finds negative assortative mating on education. All empirical studies find positive correlations between the educations of spouses, and the hypothesis of educational homogamy has never been rejected. Therefore, the question usually boils down to an issue of degree of homogamy over time and across countries (Smits et al., 1998; Mare, 1991; Halpin and Chan, 2002).

However, in the case of marriage migration, which can be viewed as a new sort of chain migration in Western Europe, we might observe negative assortative mating as a consequence of exchange between the spouses. Revisiting Gitmez and Wilpert (1987) and Van Amersfoort (1995), marriage migration is described as an exchange of favourable living conditions against for instance a high bride price. Or, in accordance with Lievens (1999), a high human capital of the immigrant could be exchanged for unspoiled norms on the side of the marriage migrant, because a young man may prefer a spouse from the country of origin, if he finds that native women and also immigrant women living in the host country are too modern and behave too freely. However, we might also see the traditional positive assortative mating, which would confirm with the observation of Kalmijn (1993) that second generation immigrants in the United States (from European origin) choose their partners on the basis of educational equality rather than on the basis of equal origin. However, Non-Western immigrants in Europe have relatively more traditional norms, which allow marriage patterns of traditional societies to persist even after migration. Smits et al. (1998) discuss status homogamy as a predecessor for educational homogamy. Earlier, the spouses matched based on social background (i.e. parental education/occupation) rather than the spouses' educational levels. ${ }^{4}$

In the empirical part of the paper, we analyse the probability that an immigrant marries a spouse from the upper part of the relevant educational distribution, while taking into account that the decision to import a spouse may be endogenous. Hence, the characteristic of main interest is education labelled marital capital $\left(M_{j}, M_{k}\right)$. We can then test whether PAM applies in the case of marriage migration or whether marriage migration matching behaviour is better described by the exchange theory. We boil down a range of attitudinal variables to two factors in order to account for differences in the preferences for importing a spouse. Below, we describe the data and then turn to the empirical analysis.

\footnotetext{
${ }^{4}$ See e.g. Blau and Duncan (1967).
} 


\section{Data description}

\subsection{Description of the data source}

The data source consists of 693 relatively young first generation immigrants from ExYugoslavia, Turkey and Pakistan. Denmark imported its 'guest workers' mainly from these three countries in the 1960s and early 1970s. The sample consists of children of the guest workers born before the arrival to Denmark. At the time of the interview in 1999, the individuals had been in Denmark at least 20 years and their age ranged from 25 to 37 years, with an average age of 33 years. ${ }^{5}$ Jakobsen (2003) reports that the survey respondents tend to be favourably selected and that the level of education reported in the survey is slightly higher than the education information for the same individual found in register data. However, we need survey information to be able to include attitudinal variables, which are important for marriage decisions. In addition, in the register data we do not have full information on the education of immigrants who had their education in the country of origin, which would be a problem especially in the case of the marriage migrant spouse. As we are concerned with the marriage decision, we select individuals who are married and not yet divorced at the time of the survey. ${ }^{6}$ That makes $77 \%$ of the sampled individuals, which means that the sample size is reduced to 535 individuals. Below, we describe the data in more detail.

Figure 1 shows the distribution of individuals over education. The level of education was extremely low because some people had not completed any education at all. Among men, about half had education beyond basic school, whereas among women $35 \%$ had education beyond basic school.

\footnotetext{
${ }^{5}$ Some of the individuals were interviewed also in 1988. We do not use this information in our analysis because the questions asked were different. Also, the two waves are in the form of an unbalanced panel with potential sample selection problems as well as an important number of missing data due to potentially non-random attrition (25\% in 1988 and $37 \%$ in 1999$)$, see Jakobsen (2003).

${ }^{6}$ We need to exclude those who divorced or separated before the survey because we do not have information about the education of their spouse, which forms the basis for the dependent variable.
} 
Figure 1. Educational level by gender.

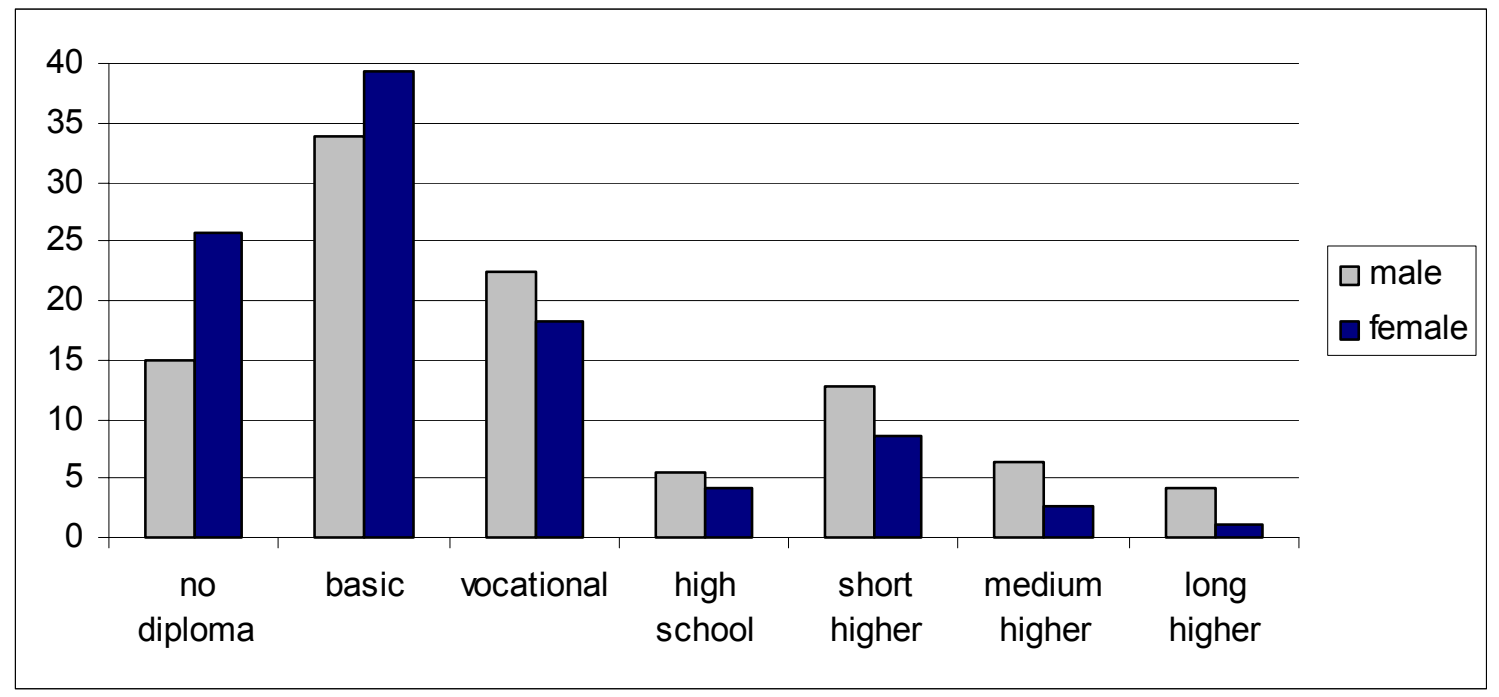

Figure 2 shows the percentage of imported partners for the different levels of education. Individuals who have imported their spouses constitute $87 \%$ of the sample, the number decreases with education. As it can be seen from the histogram, more than $90 \%$ of the individuals with no diploma have imported their partner, whereas "only" $43 \%$ of those with a long higher education have imported their partner.

Figure 2. Proportion of immigrants who have imported their partner by education.

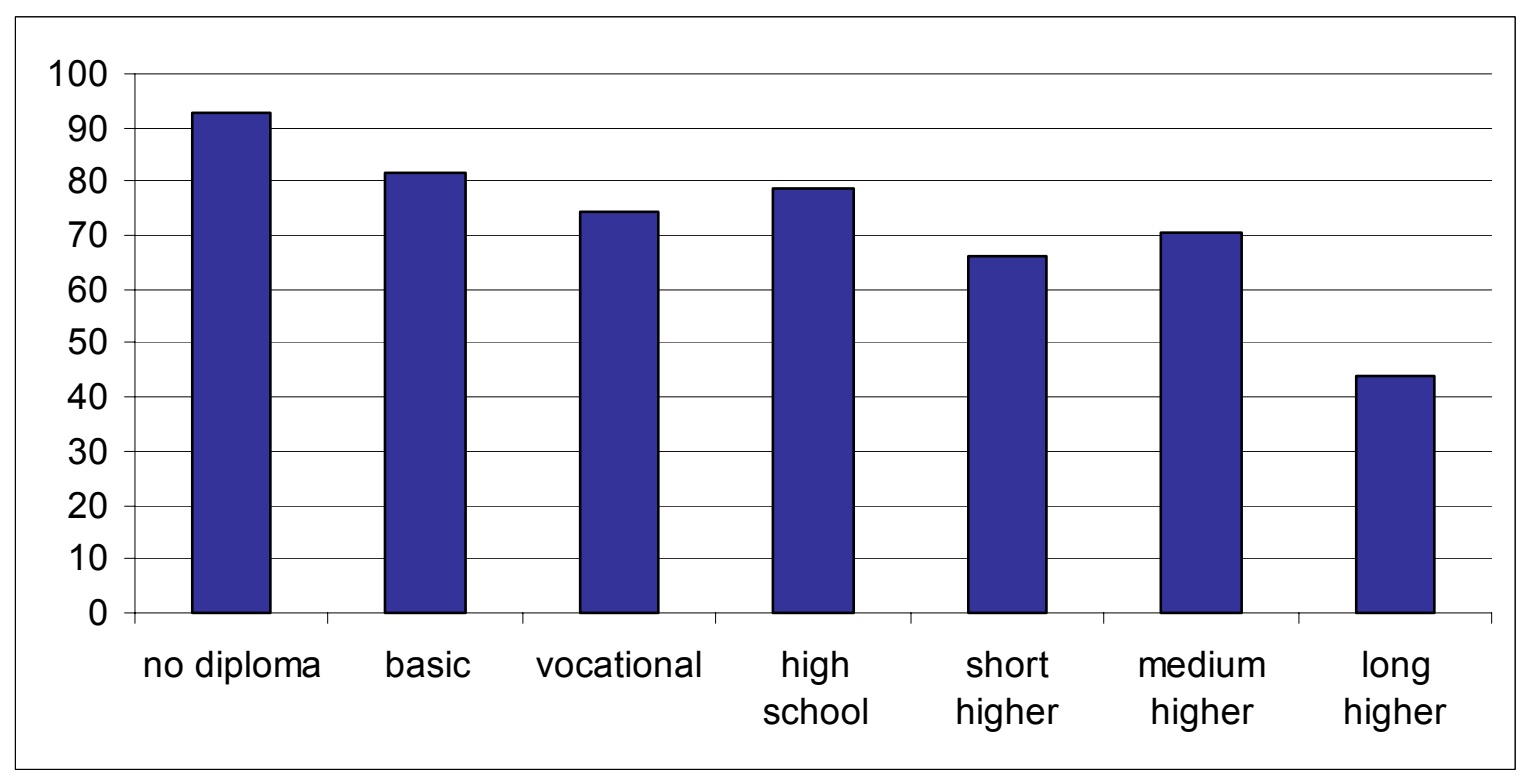

\subsection{The education variables}

The focus of this paper is on educational homogamy in marriage behaviour of immigrants in Denmark, which means that the dependent variable is an indicator for marrying a relatively well-educated spouse. To test PAM, the main explanatory variable is a similar education variable for the interviewed individual itself. 
As the interviewed immigrants have spent a significant part of their childhood in Denmark, their education has mainly been obtained in Denmark. The completed education is represented by seven categories: no diploma, primary education, high school, vocational school, short higher education, medium higher education and long higher education. The variable "no diploma" refers to the individuals who have no education or who have not completed primary school, which is compulsory (9 or 10 years in Denmark). After primary education, pupils can start either at high school or at a vocational school (apprenticeship), or leave the formal educational system. Qualifying educations consist of vocational education or a completed 'higher education', which may be either 'short' (2-4 years, e.g. laboratory technician, dental hygienist and other mainly technical educations), 'medium' (3-4 years, e.g. teachers, nurses, engineers, bachelors) or 'long' (5-6 years, university). As a rule of thumb, higher educations demand completed high-school qualifications.

The idea is to test whether individuals from the higher (lower) part of the educational distribution systematically tend to marry spouses from the higher (lower) part of their educational distribution. We are concerned with the level of education at the time of the marriage rather than at the time of the survey, which resembles an assumption of no foresight. ${ }^{7}$ This is computed by use of age at marriage. Computations are based on the assumption that individuals enrol and complete at standard ages. We create a variable showing whether the level of education at the time of the marriage was above the median in the gender-specific distribution.

The variable for whether the interviewed individual is well-educated is created by dividing the interviewed individuals by gender and country of origin. For each individual, we determine their percentile rank in the appropriate educational distribution for their demographic group as defined by gender and country of origin. Then we create an indicator for whether they have an education above the median in their distribution and this indicator is included as an explanatory variable in the regression analysis. For the spouses, a similar variable (the dependent variable of the analysis) is created while computing the percentile rank in the educational distribution of the relevant demographic group as defined by gender and country of origin of their partner. Hence, two dichotomous variables are created as simple measures for the two partners' educational attainment relative to the relevant distribution. In the empirical analysis, we investigate the sensitivity of the results to the choice of the median as the threshold.

Table A1 in Appendix A shows that about one third of the immigrants and fewer among their spouses have education above the median. Table A2 gives more details about the dependent variable and shows that the median persons (both individual and the potentially imported spouse) from Pakistan have high-school education, whereas the Turks and the females from

\footnotetext{
${ }^{7}$ Jakobsen and Smith (2003) are concerned about the opposite relationship, since they analyse how marriage affects the educational career for this sample.
} 
Ex-Yugoslavia only have basic education. It is striking that the male spouses have lower education than the female spouses, but that may be a result of PAM in action since the female immigrants have lower education than the male immigrants, and therefore they would marry lower educated spouses if they follow the pattern of PAM.

It is implicitly assumed that educations of spouses from different countries of origin are comparable, which means that education of Danish spouses is comparable to education of spouses imported from Turkey, Pakistan and Ex-Yugoslavia.

\subsection{Other variables}

Besides the education variables, the main variable of interest is the "type" of spouse. We construct a dichotomous variable taking the value 1 if the individual is married to or cohabit with a marriage migrant taking the value 0 if married to or cohabit with another type of partner. A marriage migrant is a person who immigrates to Denmark for the purpose of getting married or engaged to an immigrant in Denmark who is from the same country of origin.

Thus, we utilise two pieces of information in constructing the first explanatory variable; that is if the spouse is from the same country of origin as the immigrant, and if the spouse or partner has been living in the country of origin before marriage or engagement. However, although we have information on whether the spouse is from and has been living in ExYugoslavia, Turkey or Pakistan, we do not have information on which one of these countries the spouse is from. Thus, we assume that people marry or get engaged to persons from their own country of origin. It is extremely rare $^{8}$ that, for example, a Turkish immigrant imports a Pakistani wife instead of a Turkish wife. Being married to 'other partner' means that the immigrant did not import a spouse from the country of origin for the purpose of getting married or engaged. Thus, the individual is married or engaged to a Dane, a Western or nonWestern immigrant who has been living in Denmark or in a country other than that of ethnic origin.

The advantage of using this data set comes from the opportunity of utilising detailed information on variables that reflect attitudes, experiences and traditions. These variables would not be available in the register data, though they are potentially important determinants of marriage behaviour of immigrants. There are more than hundred variables that are thought to reflect preferences for marriage migration among the migrants, and some data reduction method is needed. We select a number of variables that are not closely related to education of the parents. Factor analysis is used to combine similar characteristics into broader categories, reducing the dimensions of attitudes of individuals to two factors. In Appendix B, the two factors are described and the twenty-five variables that they summarize are listed. The

\footnotetext{
${ }^{8}$ See Matthiessen (2000).
} 
included 'raw' variables mainly reflect the type and frequency of arguments with parents and their attitude and ranking of Danish versus source country culture.

The first factor is labelled conflicts with parents, and it reflects whether the individual argued with the parents about leaving home, choosing a partner, education, work and about leisure activities. The degree of conflicts with parents may indicate the willingness of the individual to challenge the norms of his/her family and source country. Nauck (1989), Phalet and Claeys (1993) and Phalet and Schonpflug (2001) argue that close family ties and support are important characteristics of non-Western immigrants, which increases the costs of nonconformist behaviour through the expected reactions of the social context. The second factor is labelled cultural assimilation, and the high loadings are associated with a preference for Danish culture for instance when it comes to gender role patterns, divorces, treatment of the old and children. These two factors are used as explanatory variables in the probit estimations describing the education of the spouse and the decision to import a spouse. Both are expected to be negatively related to importing a spouse, and they are meant to serve as instruments for the import decision.

The factors are orthogonal by construction, and the mean is zero, whereas the standard deviation is unity, also by construction. Table A1 shows the means of the factors for the sample of people who were married at the time of survey by gender and country of origin. Substantial differences show up in the means. Women are more culturally assimilated than men, whereas men have more conflicts with parents than women. Ex-Yugoslavian immigrants are more culturally assimilated and have more arguments with parents than immigrants from the other countries of origin.

We also try to include variables that are related to work effort and attachment to employment, such as whether the individual was a full-time worker or not and information on unemployment frequency. With regard to unemployment frequency, two variables are used, where the first one shows if the individual has been unemployed all the time within the last 35 years, and the second one shows if he/she has never been unemployed within this period. Although we have this information at the time of the survey rather than at the time of the marriage, we intend to utilise it as general indicators of labour market attachment, in spite of the various weaknesses of these variables to indicate labour market attachment fully. We also test the effect of changing eligibility rules for imported spouses over the relevant period. However, none of these variables seem to have explanatory power, and therefore we are not going to touch upon them in the next section.

\section{Empirical analysis}

In the empirical analysis, we study the education of immigrants and their spouses. We test two hypotheses: the exchange hypothesis and the hypothesis of positive assortative matching (PAM). First, we compare the education of two spouses by use of simple tests. After that, we 
investigate what determines the probability of marrying a spouse with an education above the median by the use of regression analysis. This allows us to test the two main hypotheses of the paper.

\subsection{Simple tests of assortative mating}

In Table 1, we present a cross table of the education of immigrants in Denmark and their spouses. The crudest absolute measure of assortative matching is the simple sum of percentages at the diagonal of this table. Here we find $45 \%$ of the sample on the diagonal, which is standard for most countries and for native Danes (Svarer, forthcoming). Hence, it seems that the stylized fact of PAM is confirmed for immigrants in Denmark.

Table 1. Cross tabulation of education of married individuals in the sample.

Education of individual

\begin{tabular}{|c|c|c|c|c|c|c|c|}
\hline \multicolumn{2}{|c|}{ Education of spouse } & $\begin{array}{c}\text { Basic school /no } \\
\text { diploma }\end{array}$ & $\begin{array}{l}\text { Vocational } \\
\text { /high school }\end{array}$ & Short higher & Medium higher & Long higher & Total \\
\hline \multicolumn{8}{|c|}{ Basic school/no } \\
\hline diploma & $\%$ of Total & 30.65 & 9.35 & 2.43 & 0.37 & 0.37 & 43.18 \\
\hline Vocational/high & Count & 109 & 70 & 36 & 19 & 9 & 243 \\
\hline school & $\%$ of Total & 20.37 & 13.08 & 6.73 & 3.55 & 1.68 & 45.42 \\
\hline \multirow[t]{2}{*}{ Short higher } & Count & 15 & 9 & 3 & 2 & 1 & 30 \\
\hline & $\%$ of Total & 2.80 & 1.68 & 0.56 & 0.37 & 0.19 & 5.61 \\
\hline \multirow[t]{2}{*}{ Medium higher } & Count & 5 & 6 & 1 & 2 & 1 & 15 \\
\hline & $\%$ of Total & 0.93 & 1.12 & 0.19 & 0.37 & 0.19 & 2.80 \\
\hline \multirow[t]{2}{*}{ Long higher } & Count & 3 & 4 & 4 & 2 & 3 & 16 \\
\hline & $\%$ of Total & 0.56 & 0.75 & 0.75 & 0.37 & 0.56 & 2.99 \\
\hline \multirow[t]{2}{*}{ Total } & Count & 296 & 139 & 57 & 27 & 16 & 535 \\
\hline & $\%$ of Total & 55.33 & 25.98 & 10.65 & 5.05 & 2.99 & 100 \\
\hline
\end{tabular}

However, Halpin and Chan (2002) remind us that this measure is very sensitive to differences in the marginal distributions of education for the two spouses and that a large diagonal sum could be due to a high aggregation level of the educational groups. Therefore, we test the correlation between the educations of the two spouses. This is done by use of Kendall's Tau which is the appropriate correlation measure between two ranked discrete variables.

Looking at Kendall's Tau in 2, we see that for most sub-groups the correlation is significantly positive and therefore confirms the above conclusion. However, when the groups are broken down by gender of the interviewed individual and by country of origin, varying patterns emerge. In particular, for individuals from Pakistan there is no systematic relationship between the educations of the two spouses. Breaking down the sample in smaller subsamples, we see that female individuals from Pakistan are less prone to marry a spouse with the same level of education compared to their male counterparts. 
Furthermore, Kendall's Tau is not significantly different from zero for males who did not import their spouse. These raw tests indicate that education may play a different role for different sub-groups. In the regression analyses in the next sub-section, we investigate the covariance of education and other background characteristics in more detail.

Table 2. Kendall's Tau for correlation of education of the two spouses.

\begin{tabular}{ll}
\hline \hline & Kendall's Tau \\
\hline All & $0.28^{*}$ \\
Males & $0.34^{*}$ \\
Females & $0.34^{*}$ \\
\hline Immigrants who are not married to m.m. & $0.25^{*}$ \\
Immigrants who are married to m.m. & $0.26^{*}$ \\
\hline Ex-Yugoslavia & $0.23^{*}$ \\
Turkey & $0.23^{*}$ \\
Pakistan & 0.09 \\
\hline Males married to m.m. & $0.37^{*}$ \\
Females married to m.m. & $0.31^{*}$ \\
Males married to other type of spouse & 0.15 \\
Females married to other type of spouse & $0.46^{*}$ \\
\hline Ex-Yugoslavian males & $0.25^{*}$ \\
Ex-Yugoslavian females & $0.39^{*}$ \\
Turkish males & $0.32^{*}$ \\
Turkish females & $0.25^{*}$ \\
Pakistani males & $0.22^{*}$ \\
Pakistani females & 0.05 \\
\hline \hline
\end{tabular}

Note: * means that the correlation is significantly different from zero at the $5 \%$ level.

\subsection{Advanced tests of the two main hypotheses}

In this section, regression models are used to test positive assortative mating and the exchange hypothesis. To test the hypothesis of PAM, we test whether individuals from the higher (lower) part of the educational distribution systematically tend to marry spouses from the higher (lower) part of their educational distribution. ${ }^{9}$ If that is the case, it is interpreted as support to the PAM hypothesis. To test the exchange hypothesis, we investigate whether individuals who import spouses systematically marry spouses higher up in the educational distribution ceteris paribus.

As a first step, we estimate univariate probit models. The dependent variable is the indicator for having married a spouse with an education above the median or not. The similar variable of the individual him- or herself is included as an explanatory variable. If the estimated coefficient is significantly positive, it is interpreted as evidence of PAM. In contrast to the

\footnotetext{
${ }^{9}$ See details in the previous section addressing the data.
} 
simple tests of assortative mating in the previous section, this approach allows us to control for other covariates such as the attitudinal variables and parental background.

The results of estimation of the univariate probit models are shown in Table 3. LR tests indicate that the model might be estimated separately by gender, ${ }^{10}$ but not for the three countries of origin. We choose to comment on the results from both the gender-specific and country-specific estimations because they are informative about robustness of the conclusions and about who drives the conclusions.

From model (1) we see that the coefficient on own education above the median is positive and significantly different from zero for all samples but Pakistanis. This lends support to PAM and confirms the picture from the simple tests presented above. To test the exchange hypothesis, we include an indicator variable for having imported the spouse. If the coefficient on this dummy variable is significantly different from zero that is seen as evidence in favour of the exchange hypothesis. A positive coefficient would indicate that education of the imported spouse is exchanged for a favourable characteristic of the immigrant (such as for instance living conditions in the host country), whereas a negative coefficient would indicate that education of the immigrant is exchanged for a favourable characteristic of the imported spouse (for instance unspoiled norms). The exchange hypothesis is not generally confirmed, but it tends to hold for men. In model (1), the coefficient on the import dummy is significant at a $10 \%$ level.

In model (2), we include an interaction effect between own education and the indicator for having imported a spouse in order to allow for systematic differences in educational mating patterns between importers and non-importers. Only for women, the PAM result is robust towards this change of specification. For the other samples, the interaction effect tends to moderate the PAM effect found in model (1). Particularly for men, the PAM result evaporates and the result in model (1) seems to be driven by the men who import spouses rather than the men who marry women in Denmark. Furthermore, the support to the exchange hypothesis is strengthened. In model (3), we include the two factors to account for attitudes. They exert no significant influence on the probability of marriage to a spouse with education above the mean, and they do not affect the conclusions. Neither the interaction term nor the factors are significant, and so far the preferred model is model (1).

\footnotetext{
${ }^{10}$ It is a borderline case. For the univariate probit models, p-values are above $10 \%$, whereas for the bivariate probit models $\mathrm{p}$ values are just below $10 \%$.
} 
Table 3. Estimation of a probit model for marriage to a spouse with education above the median.

\begin{tabular}{|c|c|c|c|c|c|c|c|c|c|c|c|c|}
\hline & \multicolumn{2}{|c|}{ All } & \multicolumn{2}{|c|}{ Women } & \multicolumn{2}{|c|}{ Men } & \multicolumn{2}{|c|}{ Turkey } & \multicolumn{2}{|c|}{ Pakistan } & \multicolumn{2}{|c|}{ Ex-Yugoslavia } \\
\hline & Mean & Std. Dev & Mean & Std. Dev & Mean & Std. Dev & Mean & Std. Dev & Mean & Std. Dev & Mean & Std. Dev \\
\hline \multicolumn{13}{|l|}{ Model (1): } \\
\hline Own educ $>$ median & 0.553 & 0.140 & 0.682 & 0.208 & 0.510 & 0.198 & 0.798 & 0.227 & 0.109 & 0.261 & 0.719 & 0.260 \\
\hline Imported spouse & -0.051 & 0.169 & 0.355 & 0.252 & -0.437 & 0.238 & -0.393 & 0.308 & -0.108 & 0.330 & 0.222 & 0.268 \\
\hline Turkey & 0.728 & 0.168 & 0.675 & 0.223 & 0.889 & 0.269 & & & & & & \\
\hline Pakistan & -0.024 & 0.181 & -0.002 & 0.242 & -0.044 & 0.284 & & & & & & \\
\hline Male & -0.668 & 0.130 & & & & & -0.663 & 0.192 & -0.742 & 0.257 & -0.552 & 0.264 \\
\hline Constant & -0.884 & 0.183 & -1.240 & 0.274 & -1.322 & 0.241 & 0.093 & 0.308 & -0.645 & 0.356 & -1.169 & 0.292 \\
\hline Log likelihood & \multicolumn{2}{|c|}{-254} & \multicolumn{2}{|c|}{-142} & \multicolumn{2}{|c|}{-109} & \multicolumn{2}{|c|}{-124} & \multicolumn{2}{|c|}{-65} & \multicolumn{2}{|c|}{-62} \\
\hline \multicolumn{13}{|l|}{ Model (2): } \\
\hline Own educ $>$ median & 0.386 & 0.282 & 0.693 & 0.458 & 0.080 & 0.378 & 1.326 & 0.687 & -0.131 & 0.580 & 0.422 & 0.410 \\
\hline Imported spouse & -0.152 & 0.223 & 0.545 & 0.376 & -0.687 & 0.299 & -0.234 & 0.366 & -0.256 & 0.453 & -0.026 & 0.373 \\
\hline Own educ*Imported spouse & 0.220 & 0.324 & -0.358 & 0.504 & 0.592 & 0.441 & -0.597 & 0.727 & 0.302 & 0.653 & 0.486 & 0.525 \\
\hline Turkey & 0.731 & 0.168 & 0.678 & 0.223 & 0.902 & 0.271 & & & & & & \\
\hline Pakistan & -0.024 & 0.181 & 0.001 & 0.243 & -0.042 & 0.287 & & & & & & \\
\hline Male & -0.679 & 0.131 & & & & & -0.651 & 0.192 & -0.759 & 0.261 & -0.575 & 0.267 \\
\hline Constant & -0.795 & 0.222 & -1.416 & 0.380 & -1.147 & 0.267 & -0.056 & 0.359 & -0.512 & 0.449 & -0.990 & 0.339 \\
\hline Log likelihood & \multicolumn{2}{|c|}{-254} & \multicolumn{2}{|c|}{-142} & \multicolumn{2}{|c|}{-108} & \multicolumn{2}{|c|}{-123} & \multicolumn{2}{|c|}{-65} & \multicolumn{2}{|c|}{-62} \\
\hline \multicolumn{13}{|l|}{ Model (3): } \\
\hline Own educ $>$ median & 0.390 & 0.283 & 0.985 & 0.461 & 0.119 & 0.381 & 1.366 & 0.687 & -0.037 & 0.606 & 0.421 & 0.411 \\
\hline Imported spouse & -0.124 & 0.232 & 0.466 & 0.390 & -0.592 & 0.307 & -0.213 & 0.374 & -0.114 & 0.519 & 0.026 & 0.388 \\
\hline Own educ*Imported spouse & 0.210 & 0.325 & -0.358 & 0.507 & 0.539 & 0.445 & -0.635 & 0.729 & 0.167 & 0.684 & 0.465 & 0.528 \\
\hline Conflicts with parents & 0.029 & 0.070 & -0.100 & 0.117 & 0.118 & 0.089 & -0.020 & 0.103 & 0.192 & 0.164 & 0.032 & 0.131 \\
\hline Culturally assimilated & 0.014 & 0.065 & -0.019 & 0.099 & 0.041 & 0.089 & 0.085 & 0.089 & -0.246 & 0.145 & 0.068 & 0.140 \\
\hline Turkey & 0.731 & 0.168 & 0.676 & 0.224 & 0.893 & 0.271 & & & & & & \\
\hline Pakistan & -0.022 & 0.182 & -0.012 & 0.243 & -0.059 & 0.290 & & & & & & \\
\hline Male & -0.680 & 0.134 & & & & & -0.628 & 0.194 & -0.993 & 0.299 & -0.560 & 0.269 \\
\hline Constant & -0.815 & 0.227 & -1.370 & 0.389 & -1.213 & 0.275 & -0.093 & 0.364 & -0.560 & 0.491 & -1.034 & 0.350 \\
\hline Log likelihood & \multicolumn{2}{|c|}{-254} & \multicolumn{2}{|c|}{-142} & \multicolumn{2}{|c|}{-107} & \multicolumn{2}{|c|}{-123} & \multicolumn{2}{|c|}{-63} & \multicolumn{2}{|c|}{-62} \\
\hline $\mathrm{N}$ & 53 & & 24 & & 25 & & 21 & & 16 & & 21 & \\
\hline
\end{tabular}

Note: Boldface indicates significance at a 5\% level, whereas italics indicate significance at a $10 \%$ level. 
Table 4. Summary of coefficients of main interest.

\begin{tabular}{|c|c|c|c|c|c|c|c|c|c|c|c|c|}
\hline & \multicolumn{2}{|c|}{ All } & \multicolumn{2}{|c|}{ Women } & \multicolumn{2}{|c|}{ Men } & \multicolumn{2}{|c|}{ Turkey } & \multicolumn{2}{|c|}{ Pakistan } & \multicolumn{2}{|c|}{ Ex-Yugoslavia } \\
\hline & Coefficient & Std. Dev. & Coefficient & Std. Dev. & Coefficient & Std. Dev. & Coefficient & Std. Dev. & Coefficient & Std. Dev. & Coefficient & Std. Dev. \\
\hline \multicolumn{13}{|l|}{ Univariate probit } \\
\hline \multicolumn{13}{|c|}{ Model without import dummy } \\
\hline Own educ $>$ median & 0.553 & 0.140 & 0.682 & 0.208 & 0.510 & 0.198 & 0.798 & 0.227 & 0.109 & 0.261 & 0.719 & 0.260 \\
\hline \multicolumn{13}{|l|}{ Model without interaction } \\
\hline Own educ $>$ median & 0.550 & 0.140 & 0.699 & 0.210 & 0.510 & 0.199 & $\mathbf{0 . 8 0 7}$ & 0.228 & 0.096 & 0.266 & 0.705 & 0.261 \\
\hline Imported spouse & -0.025 & 0.176 & 0.273 & 0.269 & -0.360 & 0.245 & -0.388 & 0.314 & -0.025 & 0.376 & 0.268 & 0.281 \\
\hline \multicolumn{13}{|l|}{ Model with interaction } \\
\hline Own educ $>$ median & 0.386 & 0.282 & 0.693 & 0.458 & 0.080 & 0.378 & 1.326 & 0.687 & -0.131 & 0.580 & 0.422 & 0.410 \\
\hline Imported spouse & -0.152 & 0.223 & 0.545 & 0.376 & -0.687 & 0.299 & -0.234 & 0.366 & -0.256 & 0.453 & -0.026 & 0.373 \\
\hline Own educ*Imported spouse & 0.220 & 0.324 & -0.358 & 0.504 & 0.592 & 0.441 & -0.597 & 0.727 & 0.302 & 0.653 & 0.486 & 0.525 \\
\hline \multicolumn{13}{|l|}{ Bivariate probit } \\
\hline \multicolumn{13}{|l|}{ Model without interaction } \\
\hline Own educ $>$ median & 0.519 & 0.153 & 0.725 & 0.218 & 0.421 & 0.214 & 0.790 & 0.236 & 0.021 & 0.245 & 0.580 & 0.338 \\
\hline Imported spouse & -0.349 & 0.544 & 0.642 & 0.554 & -1.357 & 0.817 & -0.554 & 1.157 & -1.451 & 0.850 & -0.360 & 0.841 \\
\hline \multicolumn{13}{|l|}{ Model with interaction } \\
\hline Own educ $>$ median & 0.328 & 0.295 & 1.054 & 0.466 & -0.050 & 0.298 & 1.319 & 0.690 & -0.135 & 0.461 & 0.248 & 0.474 \\
\hline Imported spouse & -0.520 & 0.601 & 0.907 & 0.628 & -2.093 & 0.681 & -0.396 & 1.118 & -1.541 & 0.872 & -0.744 & 0.994 \\
\hline Own educ*Imported spouse & 0.243 & 0.321 & -0.401 & 0.501 & 0.626 & 0.354 & -0.598 & 0.727 & 0.213 & 0.536 & 0.482 & 0.492 \\
\hline
\end{tabular}

Note: Information on parents is not included. Gender and country of origin included where appropriate.

Note: Boldface indicates significance at a $5 \%$ level, whereas italics indicate significance at a $10 \%$ level. 
There might be unobserved factors such as norms, traditions, attitudes or preferences that affect both the decision to import a partner and the education of the future partner. If that is the case, the indicator for importing a partner would be endogenous in the estimated probit model. We test that by estimating a bivariate probit model. The results are summarized in Table 4, and the full set of results is presented in Appendix C.

As instruments for the indicator for importing a spouse, we use the two factors: conflicts with parents and cultural assimilation. The strength and validity of the instruments are confirmed for most samples, and both have highly significant negative effects on the probability of importing a spouse as expected. We find that the more the immigrant argues with his or her parents and the more he or she prefers Danish culture, the less likely it is that he or she imports a partner. The finding that the two factors are important determinants of importing a spouse may be interpreted as evidence that the functional form of the utility functions $(f($.$) and$ $g()$.$) actually differs across those importing a spouse and those not importing a spouse. The$ negative effects of the factors support our argument that the decision to import a spouse and the subsequent decision about whom to import are household decisions rather than solely individual decisions. In case of no import, the decision is more likely an individual decision. This explains the different functional forms of $f($.$) and g($.$) between the two groups. In$ addition to the factors, gender and country of origin affect the probability of marrying a person from the home country. Turkish and Pakistani immigrants have higher probabilities of importing a partner than the Ex-Yugoslavians have (reference category), hence for Turks and Pakistanis there is an excess probability of importing a spouse, which is not explained by differences in the included variables.

For all samples, the correlation coefficient in the bivariate probit model is not rejected to be zero, which indicates that two univariate probit equations would be preferred over the bivariate probit model. Therefore, we only use the results of the bivariate probit model as a robustness check.

Coefficient estimates for the total sample are largely unchanged as well as the consistent support to PAM for women. It is worth noting, that the coefficient to the import dummy is nowhere negative for women, it is always positive but insignificant. For men, the negative effect of importing a spouse on the education of the spouse is very strong, and the PAM conclusion is now accepted at a 10\% significance level for men having an imported spouse. Hence, male immigrants who import a spouse tend to have lower educated spouses, but the probability of getting a spouse with education above the median increases with own education. For male immigrants who do not import a spouse, we see no systematic relationship between the educations of the spouses. This is exactly the same as Kendall's Tau in Table 2. 
Looking at the country-specific results, the only change is seen for Pakistanis, who also have the largest and most well-determined correlation coefficient. The coefficient to the import dummy becomes negative and significant at a $10 \%$ level. This is a vague indication that education of the immigrant is exchanged for favourable characteristics of the imported spouse, such as unspoiled norms.

In the bivariate probit model, the estimated effects for conflicts with parents and cultural assimilation are generally estimated to have a negative effect on the likelihood of importing a spouse. The finding of a negative effect of spouse import for men and Pakistanis may therefore be interpreted as indirect evidence that a high level of cultural assimilation and conflicts with parents works as an exchange mechanism resulting in a better educated spouse through less spouse import. In the case of an instrumental variables estimation procedure, this is labelled the local average treatment effect (LATE) in the experimental literature (Angrist and Kruger, 1999).

To sum up, the main conclusion of this section is that only for women we find evidence of PAM regardless of the specification of the model. For men, there tends to be PAM, but the conclusion is not robust towards changes of the specification, and the result seems to hold mainly for spouse importers. We always reject PAM for Pakistanis, whereas we almost consistently confirm PAM for Turks.

In general, the results are in accordance with the study for the US by Kalmijn (1993), who reports a high focus on education as a sorting mechanism, among immigrants. However, we find important exceptions to this trend, for Pakistanis and male spouse importers. The analysis does not directly reveal why this is the case. It may be that these individuals match on status (as reflected in e.g. kinship or on other networks) rather than on education. This would be consistent with marriage patterns of more traditional societies. As seen in Blau and Duncan (1967) and discussed by Smits et al. (1998), earlier studies focus on status homogamy, which means a close relationship between the social backgrounds of the two spouses.

\subsection{Sensitivity analysis}

So far, we have studied PAM by testing whether there is a systematic tendency that an immigrant with an education above (below) the median marries a spouse with an education above (below) the median. The choice of median as the threshold is arbitrary. In Table 5, we investigate how the conclusions about PAM and exchange are affected by changing the thresholds. We change the thresholds for the individual and the spouse simultaneously to 25 , 40 and $75 \%$, respectively. For women, we see that a threshold of $75 \%$ means that PAM only holds for women who do not import spouses. Thus, if a woman is above the $75^{\text {th }}$ percentile of her educational distribution, she would not necessarily obtain a spouse who matches her position in the distribution if she imports a partner. However, if she marries a non-imported 
man, she is likely to match positively on education. For the sample of males, we see that the coefficient to the import dummy tends to be negative. The lower the threshold, the more likely it is that the coefficient is negative, and similarly for the total sample. This means that the probability of getting a spouse with an education above the lowest quartile is lower if the spouse is imported. This result reflects the fact that males import females with no education at all. For Turkey it is seen, that the higher the threshold is, the more stable is the PAM result, whereas the opposite is the case for Ex-Yugoslavia.

Table 5. Sensitivity analysis/robustness check.

\begin{tabular}{|c|c|c|c|c|c|c|c|c|c|c|c|}
\hline & \multicolumn{4}{|c|}{ All } & \multicolumn{3}{|c|}{ Women } & \multicolumn{4}{|c|}{ Men } \\
\hline & $25 \%$ & $40 \%$ & $50 \%$ & $75 \%$ & $25 \%, 40 \%$ & $50 \%$ & $75 \%$ & $25 \%$ & $40 \%$ & $50 \%$ & $75 \%$ \\
\hline $\begin{array}{l}\text { Model (1): } \\
\text { Own educ }>\text { median }\end{array}$ & 0.256 & 0.379 & 0.553 & 0.450 & 0.311 & 0.682 & 0.391 & 0.240 & 0.517 & 0.510 & 0.566 \\
\hline $\begin{array}{l}\text { Log likelihood } \\
\text { Model (2): }\end{array}$ & -346 & -302 & -254 & -168 & -146 & -142 & -109 & -176 & -134 & -109 & -58 \\
\hline Own educ $>$ median & 0.310 & 0.277 & 0.386 & 0.553 & 0.788 & 0.969 & 1.116 & -0.040 & 0.552 & 0.080 & 0.076 \\
\hline Imported spouse & -0.282 & -0.340 & -0.152 & -0.069 & 0.612 & 0.545 & 0.460 & -0.849 & -0.680 & -0.687 & -0.740 \\
\hline Own educ*Imported spouse & -0.068 & 0.133 & 0.220 & -0.152 & -0.555 & -0.358 & -1.024 & 0.354 & -0.049 & 0.592 & 0.828 \\
\hline Log likelihood & -346 & -302 & -254 & -168 & -146 & -142 & -107 & -175 & -134 & -108 & -57 \\
\hline
\end{tabular}

\begin{tabular}{|c|c|c|c|c|c|c|c|c|c|c|c|c|}
\hline & \multicolumn{4}{|c|}{ Turkey } & \multicolumn{4}{|c|}{ Pakistan } & \multicolumn{4}{|c|}{ Ex-Yugoslavia } \\
\hline & $25 \%$ & $40 \%$ & $50 \%$ & $75 \%$ & $25 \%$ & $40 \%$ & $50 \%$ & $75 \%$ & $25 \%$ & $40 \%$ & $50 \%$ & $75 \%$ \\
\hline \multicolumn{13}{|l|}{ Model (1): } \\
\hline Own educ $>$ median & -0.057 & 0.359 & 0.798 & $\mathbf{0 . 8 5 7}$ & 0.341 & 0.128 & 0.109 & 0.126 & 0.592 & 0.639 & 0.719 & 0.555 \\
\hline Imported spouse & -0.459 & -0.429 & -0.393 & -0.868 & -0.068 & -0.114 & -0.108 & -0.109 & -0.270 & -0.260 & 0.222 & 0.181 \\
\hline Log likelihood & -130 & -128 & -124 & -34 & -102 & -65 & -65 & -65 & -91 & -91 & -62 & -64 \\
\hline \multicolumn{13}{|l|}{ Model (2): } \\
\hline Own educ $>$ median & -0.278 & 0.344 & 1.326 & 1.657 & -0.486 & -0.280 & -0.131 & 0.151 & 0.872 & 0.683 & 0.422 & 0.354 \\
\hline Imported spouse & -0.638 & -0.438 & -0.234 & -0.422 & -0.754 & -0.386 & -0.256 & -0.096 & 0.010 & -0.231 & -0.026 & 0.068 \\
\hline Own educ*Imported spouse & 0.240 & 0.017 & -0.597 & -1.057 & 0.996 & 0.498 & 0.302 & -0.033 & -0.442 & -0.076 & 0.486 & 0.386 \\
\hline Log likelihood & -130 & -128 & -123 & -34 & -100 & -64 & -65 & -65 & -91 & -91 & -62 & -64 \\
\hline
\end{tabular}

\section{Conclusion}

In this paper, we shed light on marriage patterns of immigrants. We test two main hypotheses, namely the hypothesis of positive assortative matching (PAM) and the exchange hypothesis. In the empirical analyses, we use survey data on children of the guest worker immigrants in Denmark, who are originally from Ex-Yugoslavia, Turkey and Pakistan.

We argue that the probability of a match between an immigrant and a marriage migrant is determined by their expected utilities from the match. The utility function depends on the household's preferences over the observable characteristics of the individual. Both the source country and the immigrant household's preferences depend upon the origin of the spouse. From the point of view of the source country household, the possibility of obtaining a residence permit in a host country with favourable wage or welfare schemes may enhance the preferences for a spouse from the host country. From the point of view of the host country household, utility may increase if the spouse is related to the household in question and has unspoiled norms and traditions. Furthermore, they might value the fact that they are able to please relatives in the country of origin. As a result, an exchange may take place, such that 
strong preferences for a specific origin of the spouse compensates for a lower level of an observable characteristic, such as education.

In the empirical analysis, we analyse the determinants of the education of the spouse. We test PAM by testing whether an individual with education above (below) a certain threshold in his or her educational distribution is more likely to marry an individual with an education above (below) the same threshold in the relevant educational distribution. We find evidence supportive of PAM for women regardless of the specification of the model. For men, there tends to be PAM, but the conclusion is not robust towards changes of the specification, and the result seems to hold mainly for spouse importers. We always reject PAM for Pakistanis, whereas we almost consistently confirm PAM for Turks. For men, we see that importing a partner reduces the probability of obtaining a well-educated spouse, which is interpreted as support to the exchange hypothesis, which would be consistent with a situation where traditional, unspoiled norms of the imported woman is traded against education.

We use both univariate and bivariate probit models, and hence we allow the import decision to be an endogenous variable in the education equation. Using the bivariate probit model shows that the effect of importing a spouse becomes even more negative and significant for men, and it becomes significant for Pakistanis. This indicates that through less spouse import, the probability of a favourable match in the marriage market is highest for those who increase their level of cultural assimilation or the amount of argument with their parents (i.e. the compliers).

\section{References}

Angrist, J. D. and A. B. Krueger (1999) "Empirical Strategies in Labor Economics", Handbook of Labor Economics, vol. 3A, 1277-1366.

Becker, G. S. (1973) "A Theory of Marriage: Part I", The Journal of Political Economy, 81(4): 813-846.

Blau, P. M. and O. D. Duncan (1967) The American Occupational Structure. New York: Wiley.

Böcker, A. (1994) "Chain Migration over Legally Closed Borders: Settled Immigrants as Bridgeheads and Gatekeepers”, Netherlands' Journal of Social Sciences, 30 (2): 87-106.

Böcker, A. (1995) "Migration Networks: Turkish Migration to Western Europe", in Causes of International Migration: Proceedings of a Workshop Luxembourg, 14-16 December, ECSCEC-EAEC, Brussels.

Celikaksoy, A. (2003) “Marriage Migration in Denmark.” Draft. 
Davis, K. (1941) "Intermarriage in Caste Societies", American Anthropologist 43 (3): 376395.

Gitmez, A. and C. Wilpert (1987) “A Micro-society or an Ethnic Community? Social Organization and Ethnicity amongst Turkish Migrants in Berlin", in J. Rex, D. Joly and C. Wilpert (eds.) Immigrant Associations in Europe, Gower Publications Comp., England.

Halpin, B. and T. W. Chan (2002) "Educational Homogamy in Ireland and the UK: Trends and Patterns", Unpublished working paper, University of Oxford.

Jakobsen, V. (2003) "Data description and analyses of representativity and validity of survey data" in PhD thesis: 'Young immigrants from the former Yugoslavia, Turkey and Pakistan: educational attainment, wages and employment', Aarhus School of Business, Denmark.

Jakobsen, V. and N. Smith (2003) "The Educational Attainment of the Children of the Danish 'Guest Worker' Immigrants.” IZA Discussion Paper \#749, IZA, Bonn.

Kalmijn, M. (1993) "Spouse Selection among the Children of European Immigrants: A Comparison of Marriage Cohorts in the 1960 Census", International Migration Review, 27 (1): 51-78.

Lievens, J. (1998) "Interethnic Marriage: Bringing in the Context through Multilevel Modeling”, European Journal of Population, 14: 117-155.

Lievens, J. (1999) "Family-Forming Migration from Turkey and Morocco to Belgium: The Demand for Marriage Partners from the Countries of Origin", The International Migration Review, 33(3): 717-744.

Mare, D. (1991) "Five Decades of Educational Assortative Mating“ American Sociological Review 56: 15-32.

Matthiessen, P. C. (2000) "Integration into the Labour Market" in The Rockwool Foundation Research Unit Newsletter.

Merton, R. K. (1941) "Intermarriage and the Social Structure: Fact and Theory." Psychiatry 4: 361-374.

Nauck, B. (1989) "Intergenerational relationships in families from Turkey and Germany", European Sociological Review, 5(3): 251-274.

Phalet, K. and W. Claeys (1993) “A Comparative Study of Turkish and Belgian Youth", Journal of Cross-cultural Psychology, 24: 319-343.

Phalet, K. and U. Schonpflug (2001) "Intergenerational Transmission in Turkish Immigrant Families: Parental Collectivism, Achievement Values and Gender Differences”, Journal of Comparative Family Studies, 32(4): 489-504. 
Qian, Z. (1999) "Who Intermarries? Education, Nativity, Region, and Interracial Marriage, 1980 and 1990.” Journal of Comparative Family Studies 30(4): 579-597.

Qian, Z., S. L. Blair and S. D. Ruf (2001) “Asian American Interracial and Interethnic Marriages: Differences by Education and Nativity", International Migration Review, 35(2): 557-586.

Smits, J., W. Ultee and J. Lammers (1998) "Educational Homogamy in 65 Countries: An Explanation of Differences in Openness Using Country-Level Explanatory Variables." American Sociological Review 63: 264-285.

Svarer, M. (forthcoming) "Is Your Love in Vain? Another Look at Premarital Cohabitation and Divorce." Forthcoming in the Journal of Human Resources.

Weiss, Y. (1997) "The Formation and Dissolution of Families: Why Marry? Who Marries Whom? and What Happens upon Divorce?", in M. R. Rosenzweig and O. Stark (eds.) Handbook of Population and Family Economics, Elsevier, Amsterdam.

Van Amersfoort, H. (1995) "From workers to immigrants: Turks and Moroccans in the Netherlands, 1965-1992", 


\section{Appendix A: Descriptives}

Table A1. Means.

\begin{tabular}{lcccccc}
\hline \hline & All & Women & Men & Turkey & Pakistan & Ex-Yugoslavia \\
\hline Spouse's educ $>$ median & 0.228 & 0.325 & 0.148 & 0.343 & 0.142 & 0.168 \\
Own educ $>$ median & 0.305 & 0.267 & 0.337 & 0.214 & 0.379 & 0.348 \\
Imported spouse & 0.787 & 0.819 & 0.759 & 0.905 & 0.817 & 0.594 \\
Conflicts with parents & -0.067 & -0.198 & 0.042 & -0.167 & -0.047 & 0.047 \\
Culturally assimilated & -0.067 & 0.129 & -0.165 & -0.016 & -0.141 & 0.068 \\
Turkey & 0.393 & 0.412 & 0.378 & 1.000 & 0.000 & 0.000 \\
Pakistan & 0.316 & 0.276 & 0.351 & 0.000 & 1.000 & 0.000 \\
Male & 0.545 & 0.000 & 1.000 & 0.524 & 0.604 & 0.510 \\
Comes from village & 0.547 & 0.543 & 0.550 & 0.690 & 0.391 & 0.523 \\
Fathers educ $>9$ years & 0.199 & 0.193 & 0.203 & 0.071 & 0.166 & 0.406 \\
Mothers educ $>$ 9 years & 0.206 & 0.235 & 0.182 & 0.029 & 0.278 & 0.368 \\
& & & & & & 169 \\
$\mathrm{~N}$ & 534 & 243 & 291 & 210 & & 155 \\
\hline
\end{tabular}

Table A2. Accumulated distribution of education.

\begin{tabular}{lcccccc}
\hline \hline & \multicolumn{3}{c}{ Female immigrants } & \multicolumn{3}{c}{ Male immigrants } \\
& Turkey & Pakistan & Ex-Yugoslavia & Turkey & Pakistan & Ex-Yugoslavia \\
\hline No diploma & 0.41 & 0.04 & 0.21 & 0.30 & 0.05 & 0.05 \\
Basic school & 0.86 & 0.42 & 0.58 & 0.72 & 0.33 & 0.32 \\
Vocational education & 0.96 & 0.72 & 0.79 & 0.82 & 0.56 & 0.72 \\
High school & 0.96 & 0.81 & 0.84 & 0.86 & 0.62 & 0.78 \\
Short higher & 0.99 & 0.94 & 0.93 & 0.94 & 0.80 & 0.92 \\
Medium higher & 0.99 & 0.99 & 0.99 & 0.98 & 0.90 & 0.99 \\
Long higher & 1.00 & 1.00 & 1.00 & 1.00 & 1.00 & 1.00 \\
$\mathrm{~N}$ & 100 & 67 & 76 & 110 & 102 & 79 \\
\hline \hline & & Female spouses & & & Male spouses & \\
& Turkey & Pakistan & Ex-Yugoslavia & Turkey & Pakistan & Ex-Yugoslavia \\
\hline Basic school/no diploma & 0.56 & 0.10 & 0.22 & 0.75 & 0.35 & 0.41 \\
Vocationa/high school & 0.91 & 0.76 & 0.75 & 0.98 & 0.92 & 0.91 \\
Short higher & 0.94 & 0.87 & 0.87 & 0.99 & 0.99 & 0.95 \\
Medium higher & 0.96 & 0.91 & 0.95 & 1.00 & 1.00 & 0.97 \\
Long higher & 1.00 & 1.00 & 1.00 & 1.00 & 1.00 & 1.00 \\
& & & & & & 100 \\
$\mathrm{~N}$ & 100 & 67 & 76 & 110 & & 79 \\
\hline
\end{tabular}

Note: Country refers to country of origin of the immigrant. 


\section{Appendix B: Factor analysis}

We restrict the number of factors to two and suppress factor loadings with an absolute value below 0.20 . We use the Varimax method.

Table B1. Rotated Component Matrix.

\section{Factor 1}

\section{Arguments with parents}

argued parents, leaving home didn't argue parents, leaving home argued parents, left home didn't argue parents, left home argued parents, spare time didn't argue parents, spare time argued parents, choice of partner argued parents, choice of edu., work didn't argue parents, choice of edu., work didn't argue parents, choice of partner
$-0,41$

$-0,34$

\section{Factor 2}

\section{Culturally assimilated}

equality of gender, Danish culture best individual freedom, Danish culture best bringing up children, Danish culture best divorces, Danish culture best equality of gender, co culture best individual freedom, co culture best divorces, co culture best treatment of old, Danish culture best bringing up children, co culture best treatment of old, co culture best feel as a Dane feel at home in DK

feel as a Ex-Yg., Turk, Pakistani feel at home in co 


\section{Appendix C: Results from estimation of bivariate probit models.}

Table C1. Results from estimation of a bivariate probit model without interaction effects.

\begin{tabular}{|c|c|c|c|c|c|c|c|c|c|c|c|c|}
\hline & \multicolumn{2}{|c|}{ All } & \multicolumn{2}{|c|}{ Women } & \multicolumn{2}{|c|}{ Men } & \multicolumn{2}{|c|}{ Turkey } & \multicolumn{2}{|c|}{ Pakistan } & \multicolumn{2}{|c|}{ Ex-Yugoslavia } \\
\hline & Coefficient & Std. Dev. & Coefficient & Std. Dev. & Coefficient & Std. Dev. & Coefficient & Std. Dev. & Coefficient & Std. Dev. & Coefficient & Std. Dev. \\
\hline \multicolumn{13}{|l|}{ Education equation } \\
\hline Own educ $>$ median & 0.519 & 0.153 & 0.725 & 0.218 & 0.421 & 0.214 & 0.790 & 0.236 & 0.021 & 0.245 & 0.580 & 0.338 \\
\hline Imported spouse & -0.349 & 0.544 & 0.642 & 0.554 & -1.357 & 0.817 & -0.554 & 1.157 & -1.451 & 0.850 & -0.360 & 0.841 \\
\hline Turkey & 0.811 & 0.212 & 0.608 & 0.255 & 1.153 & 0.302 & & & & & & \\
\hline Pakistan & 0.045 & 0.214 & -0.071 & 0.271 & 0.158 & 0.307 & & & & & & \\
\hline Male & -0.680 & 0.130 & & & & & -0.661 & 0.193 & -0.792 & 0.243 & -0.600 & 0.259 \\
\hline Constant & -0.681 & 0.408 & -1.437 & 0.425 & -0.692 & 0.684 & 0.239 & 1.062 & 0.650 & 0.850 & -0.710 & 0.738 \\
\hline \multicolumn{13}{|l|}{ Import equation } \\
\hline Own educ $>$ median & -0.359 & 0.140 & -0.472 & 0.230 & -0.259 & 0.186 & -0.224 & 0.287 & -0.336 & 0.239 & -0.456 & 0.224 \\
\hline Conflicts with parents & -0.343 & 0.064 & -0.575 & 0.118 & -0.247 & 0.077 & -0.324 & 0.119 & -0.450 & 0.114 & -0.281 & 0.105 \\
\hline Culturally assimilated & -0.217 & 0.071 & -0.272 & 0.129 & -0.167 & 0.085 & -0.160 & 0.136 & -0.083 & 0.139 & -0.279 & 0.111 \\
\hline Turkey & 1.019 & 0.165 & 0.717 & 0.254 & 1.178 & 0.229 & & & & & & \\
\hline Pakistan & 0.701 & 0.162 & 0.699 & 0.283 & 0.674 & 0.205 & & & & & & \\
\hline Male & -0.255 & 0.141 & & & & & 0.095 & 0.273 & -0.383 & 0.283 & -0.410 & 0.218 \\
\hline Constant & 0.549 & 0.141 & 0.705 & 0.196 & 0.206 & 0.152 & 1.335 & 0.200 & 1.370 & 0.250 & 0.669 & 0.189 \\
\hline 。 & 0.184 & 0.316 & -0.194 & 0.339 & 0.546 & 0.452 & 0.087 & 0.604 & 0.805 & 0.390 & 0.376 & 0.501 \\
\hline
\end{tabular}

Tests

${ }^{\circ} \varphi ! \sigma^{\circ}{ }^{\circ} \varphi !$

0.33

0.31

0.84

0.02

1.17

0.45

Validity of instruments ${ }^{2}$

Both factors, F-stat., ${ }^{2}(2)$

$0.00 \quad 0.77$

Conflicts with $\mathrm{p}+\mathrm{A} 56$ arents, t-stat

Culturally assimilated, t-stat.

$\begin{array}{ll}0.00 & 0.77 \\ \mathbf{0 . 0 3} & -0.68\end{array}$

Strength of instruments ${ }^{3}$

$\begin{array}{ll}\mathbf{0 . 0 3} & -0.68 \\ 0.01 & -0.01\end{array}$

LR test parental variables $(\mathrm{df}=6)^{4}$

$-0.01$

$36.40 \quad 28.49$

Log likelihood

$-8.10$

$\mathbf{N}$

$-481$

$-4.63$

534

-227
243

\begin{tabular}{cc}
$\mathbf{1 1 . 0 9}$ & 0.88 \\
$\mathbf{2 . 9 4}$ & -0.57 \\
0.04 & 0.89 \\
$\mathbf{1 3 . 0 7}$ & $\mathbf{8 . 2 5}$ \\
-7.45 & -15.64 \\
-246 & -185 \\
291 & 210 \\
\hline
\end{tabular}

6.13

6.13
3.75

0.08

$-0.57$

$-0.28$

$0.89-1.31$

$\mathbf{1 5 . 9 8}$

$-8.45$

Notes: 1. Bold letters indicate significance at a 5\% level, whereas italics indicate significance at a 10\% level. 2. Test of exclusion restrictions in the education equation. 3. F-test for joint significance of the instruments in the import equation.

4. LR test for including education of parents and coming from a village. 
Table C2. Results from estimation of a bivariate probit model with interaction effects.

\begin{tabular}{|c|c|c|c|c|c|c|c|c|c|c|c|c|}
\hline & \multicolumn{2}{|c|}{ All } & \multicolumn{2}{|c|}{ Women } & \multicolumn{2}{|c|}{ Men } & \multicolumn{2}{|c|}{ Turkey } & \multicolumn{2}{|c|}{ Pakistan } & \multicolumn{2}{|c|}{ Ex-Yugoslavia } \\
\hline & Coefficient & Std. Dev. & Coefficient & Std. Dev. & Coefficient & Std. Dev. & Coefficient & Std. Dev. & Coefficient & Std. Dev. & Coefficient & Std. Dev. \\
\hline \multicolumn{13}{|l|}{ Education equation } \\
\hline Own educ $>$ median & 0.328 & 0.295 & 1.054 & 0.466 & -0.050 & 0.298 & 1.319 & 0.690 & -0.135 & 0.461 & 0.248 & 0.474 \\
\hline Imported spouse & -0.520 & 0.601 & 0.907 & 0.628 & -2.093 & 0.681 & -0.396 & 1.118 & -1.541 & 0.872 & -0.744 & 0.994 \\
\hline Own educ*Imported spouse & 0.243 & 0.321 & -0.401 & 0.501 & 0.626 & 0.354 & -0.598 & 0.727 & 0.213 & 0.536 & 0.482 & 0.492 \\
\hline Turkey & 0.829 & 0.213 & 0.598 & 0.255 & 1.260 & 0.265 & & & & & & \\
\hline Pakistan & 0.057 & 0.215 & -0.081 & 0.270 & 0.254 & 0.281 & & & & & & \\
\hline Male & -0.694 & 0.131 & & & & & -0.648 & 0.193 & -0.807 & 0.247 & -0.627 & 0.257 \\
\hline Constant & -0.541 & 0.458 & -1.669 & 0.507 & -0.129 & 0.578 & 0.091 & 1.029 & 0.726 & 0.860 & -0.414 & 0.869 \\
\hline \multicolumn{13}{|l|}{ Import equation } \\
\hline Own educ $>$ median & -0.362 & 0.140 & -0.478 & 0.230 & -0.290 & 0.182 & -0.219 & 0.288 & -0.357 & 0.244 & -0.462 & 0.224 \\
\hline Conflicts with parents & -0.343 & 0.064 & -0.575 & 0.118 & -0.238 & 0.074 & -0.325 & 0.118 & -0.446 & 0.116 & -0.277 & 0.105 \\
\hline Culturally assimilated & -0.217 & 0.071 & -0.269 & 0.129 & -0.161 & 0.082 & -0.161 & 0.137 & -0.086 & 0.139 & -0.276 & 0.111 \\
\hline Turkey & 1.018 & 0.165 & 0.717 & 0.254 & 1.147 & 0.224 & & & & & & \\
\hline Pakistan & 0.702 & 0.162 & 0.697 & 0.283 & 0.667 & 0.205 & & & & & & \\
\hline Male & -0.258 & 0.142 & & & & & 0.095 & 0.272 & -0.384 & 0.284 & -0.414 & 0.219 \\
\hline Constant & 0.552 & 0.142 & 0.708 & 0.196 & 0.226 & 0.153 & 1.334 & 0.197 & 1.380 & 0.254 & 0.675 & 0.191 \\
\hline$\pi$ & 0.220 & 0.329 & -0.229 & 0.331 & 0.797 & 0.305 & 0.087 & 0.568 & 0.796 & 0.405 & 0.462 & 0.562 \\
\hline \multicolumn{13}{|l|}{ Tests } \\
\hline$\pi \chi\left|\sigma \tau^{\pi} \pi \chi\right|$ & \multicolumn{2}{|c|}{0.43} & \multicolumn{2}{|c|}{0.44} & \multicolumn{2}{|c|}{1.67} & \multicolumn{2}{|c|}{0.02} & \multicolumn{2}{|c|}{1.12} & \multicolumn{2}{|c|}{0.52} \\
\hline \multicolumn{13}{|l|}{ Validity of instruments ${ }^{2}$} \\
\hline Both factors, F-test, $\pi^{2}(2)$ & \multicolumn{2}{|c|}{0.05} & \multicolumn{2}{|c|}{0.35} & \multicolumn{2}{|c|}{10.42} & \multicolumn{2}{|c|}{0.94} & \multicolumn{2}{|c|}{6.96} & \multicolumn{2}{|c|}{0.55} \\
\hline Conflicts with parents, t-test & \multicolumn{2}{|c|}{-0.17} & \multicolumn{2}{|c|}{-0.53} & \multicolumn{2}{|c|}{1.34} & \multicolumn{2}{|c|}{-0.46} & \multicolumn{2}{|c|}{3.57} & \multicolumn{2}{|c|}{-0.52} \\
\hline Culturally assimilated, t-test & \multicolumn{2}{|c|}{-0.05} & 0.08 & & -0.0 & & 0.95 & & -2.20 & & -0.02 & \\
\hline Strength of instruments ${ }^{3}$ & 36.3 & & 28.2 & & 12.0 & & 8.28 & & 15.12 & & 11.38 & \\
\hline Log likelihood & -48 & & -227 & & -24 & & -184 & & -132 & & -157 & \\
\hline $\mathbf{N}$ & 534 & & 243 & & 291 & & 210 & & 169 & & 155 & \\
\hline
\end{tabular}

Notes: 1. Bold letters indicate significance at a 5\% level, whereas italics indicate significance at a $10 \%$ level. 2. Test of exclusion restrictions in the education equation. 3. F-test for joint significance

of the instruments in the import equation. 
Department of Economics:

Skriftserie/Working Paper:

2002:

WP 02-1 Peter Jensen, Michael Rosholm and Mette Verner: A Comparison of Different Estimators for Panel Data Sample Selection Models. ISSN 1397-4831.

WP 02-2 Erik Strøjer Madsen, Camilla Jensen and Jørgen Drud Hansen: Scale in Technology and Learning-by-doing in the Windmill Industry. ISSN 1397-4831.

WP 02-3 Peter Markussen, Gert Tinggaard Svendsen and Morten Vesterdal: The political economy of a tradable GHG permit market in the European Union. ISSN 13974831 .

WP 02-4 Anders Frederiksen og Jan V. Hansen: Skattereformer: Dynamiske effekter og fordelingskonsekvenser. ISSN 1397-4831.

WP 02-5 Anders Poulsen: On the Evolutionary Stability of Bargaining Inefficiency. ISSN $1397-4831$.

WP 02-6 Jan Bentzen and Valdemar Smith: What does California have in common with Finland, Norway and Sweden? ISSN 1397-4831.

WP 02-7 Odile Poulsen: Optimal Patent Policies: A Survey. ISSN 1397-4831.

WP 02-8 Jan Bentzen and Valdemar Smith: An empirical analysis of the interrelations among the export of red wine from France, Italy and Spain. ISSN 1397-4831.

WP 02-9 A. Goenka and O. Poulsen: Indeterminacy and Labor Augmenting Externalities. ISSN 1397-4831.

WP 02-10 Charlotte Christiansen and Helena Skyt Nielsen: The Educational Asset Market: A Finance Perspective on Human Capital Investment. ISSN 1397-4831.

WP 02-11 Gert Tinggaard Svendsen and Morten Vesterdal: CO2 trade and market power in the EU electricity sector. ISSN 1397-4831.

WP 02-12 Tibor Neugebauer, Anders Poulsen and Arthur Schram: Fairness and Reciprocity in the Hawk-Dove game. ISSN 1397-4831.

WP 02-13 Yoshifumi Ueda and Gert Tinggaard Svendsen: How to Solve the Tragedy of the Commons? Social Entrepreneurs and Global Public Goods. ISSN 1397-4831.

WP 02-14 Jan Bentzen and Valdemar Smith: An empirical analysis of the effect of labour market characteristics on marital dissolution rates. ISSN 1397-4831. 
WP 02-15 Christian Bjørnskov and Gert Tinggaard Svendsen: Why Does the Northern Light Shine So Brightly? Decentralisation, social capital and the economy. ISSN 13974831 .

WP 02-16 Gert Tinggaard Svendsen: Lobbyism and $\mathrm{CO}_{2}$ trade in the EU. ISSN 1397-4831.

WP 02-17 Søren Harck: Reallønsaspirationer, fejlkorrektion og reallønskurver. ISSN 13974831.

WP 02-18 Anders Poulsen and Odile Poulsen: Materialism, Reciprocity and Altruism in the Prisoner's Dilemma - An Evolutionary Analysis. ISSN 1397-4831.

WP 02-19 Helena Skyt Nielsen, Marianne Simonsen and Mette Verner: Does the Gap in Family-friendly Policies Drive the Family Gap? ISSN 1397-4831.

2003:

WP 03-1 Søren Harck: Er der nu en strukturelt bestemt langsigts-ledighed I SMEC?: Phillipskurven i SMEC 99 vis-à-vis SMEC 94. ISSN 1397-4831.

WP 03-2 Beatrice Schindler Rangvid: Evaluating Private School Quality in Denmark. ISSN 1397-4831.

WP 03-3 Tor Eriksson: Managerial Pay and Executive Turnover in the Czech and Slovak Republics. ISSN 1397-4831.

WP 03-4 Michael Svarer and Mette Verner: Do Children Stabilize Marriages? ISSN 13974831 .

WP 03-5 Christian Bjørnskov and Gert Tinggaard Svendsen: Measuring social capital - Is there a single underlying explanation? ISSN 1397-4831.

WP 03-6 Vibeke Jakobsen and Nina Smith: The educational attainment of the children of the Danish 'guest worker' immigrants. ISSN 1397-4831.

WP 03-7 Anders Poulsen: The Survival and Welfare Implications of Altruism When Preferences are Endogenous. ISSN 1397-4831.

WP 03-8 Helena Skyt Nielsen and Mette Verner: Why are Well-educated Women not Fulltimers? ISSN 1397-4831.

WP 03-9 Anders Poulsen: On Efficiency, Tie-Breaking Rules and Role Assignment Procedures in Evolutionary Bargaining. ISSN 1397-4831.

WP 03-10 Anders Poulsen and Gert Tinggaard Svendsen: Rise and Decline of Social Capital - Excess Co-operation in the One-Shot Prisoner's Dilemma Game. ISSN 13974831 . 
WP 03-11 Nabanita Datta Gupta and Amaresh Dubey: Poverty and Fertility: An Instrumental Variables Analysis on Indian Micro Data. ISSN 1397-4831.

WP 03-12 Tor Eriksson: The Managerial Power Impact on Compensation - Some Further Evidence. ISSN 1397-4831.

WP 03-13 Christian Bjørnskov: Corruption and Social Capital. ISSN 1397-4831.

WP 03-14 Debashish Bhattacherjee: The Effects of Group Incentives in an Indian Firm - Evidence from Payroll Data. ISSN 1397-4831.

WP 03-15 Tor Eriksson och Peter Jensen: Tidsbegränsade anställninger - danska erfarenheter. ISSN 1397-4831.

WP 03-16 Tom Coupé, Valérie Smeets and Frédéric Warzynski: Incentives, Sorting and Productivity along the Career: Evidence from a Sample of Top Economists. ISSN 1397-4831.

WP 03-17 Jozef Koning, Patrick Van Cayseele and Frédéric Warzynski: The Effects of Privatization and Competitive Pressure on Firms' Price-Cost Margins: Micro Evidence from Emerging Economies. ISSN 1397-4831.

WP 03-18 Urs Steiner Brandt and Gert Tinggaard Svendsen: The coalition of industrialists and environmentalists in the climate change issue. ISSN 1397-4831.

WP 03-19 Jan Bentzen: An empirical analysis of gasoline price convergence for 20 OECD countries. ISSN 1397-4831.

WP 03-20 Jan Bentzen and Valdemar Smith: Regional income convergence in the Scandinavian countries. ISSN 1397-4831.

WP 03-21 Gert Tinggaard Svendsen: Social Capital, Corruption and Economic Growth: Eastern and Western Europe. ISSN 1397-4831.

WP 03-22 Jan Bentzen and Valdemar Smith: A Comparative Study of Wine Auction Prices: Mouton Rothschild Premier Cru Classé. ISSN 1397-4831.

WP 03-23 Peter Guldager: Folkepensionisternes incitamenter til at arbejde. ISSN 1397-4831.

WP 03-24 Valérie Smeets and Frédéric Warzynski: Job Creation, Job Destruction and Voting Behavior in Poland. ISSN 1397-4831.

WP 03-25 Tom Coupé, Valérie Smeets and Frédéric Warzynski: Incentives in Economic Departments: Testing Tournaments? ISSN 1397-4831.

WP 03-26 Erik Strøjer Madsen, Valdemar Smith and Mogens Dilling-Hansen: Industrial clusters, firm location and productivity - Some empirical evidence for Danish firms. ISSN 1397-4831. 
WP 03-27 Aycan Çelikaksoy, Helena Skyt Nielsen and Mette Verner: Marriage Migration: Just another case of positive assortative matching? ISSN 1397-4831. 